\title{
Penerapan Model Pembelajaran Penemuan Mengintegrasikan Laboratorium Virtual dan Hots untuk Meningkatkan Hasil Pembelajaran Siswa SMA Kelas XI
}

\author{
Asrizal $^{1)}$, Arnel Hendri ${ }^{2)}$, Hidayati ${ }^{1)}$, Festiyed $^{1)}$ \\ ${ }^{1)}$ Dosen Jurusan Fisika, FMIPA Universitas Negeri Padang \\ ${ }^{2)}$ Guru Fisika SMA Negeri 10 Padang \\ asrizal@fmipa.unp.ac.id
}

\begin{abstract}
Science learning should gives a good scientific process experience and promotes high level thinking skills on students. However, the real conditions show that the both scientific process and integration of high order thinking can't be been applied well. The solution to this problem is the discovery learning model by integrating virtual laboratory and high order thinking. The objective of the research was to investigate the effects of the application of the discovery learning model by integrating virtual laboratory and high order thinking to improve learning outcomes of students. The type of research is classroom action research with a cycle model. The discovery learning model was applied on grade XI MIA 1 students in SMAN 10 Padang. The instrument for collecting data consisted of written test for knowledge aspect and problem solving skill, observation sheet for attitudes aspect, and performance assessment sheet for science process skills aspect. The data analysis technique that used were descriptive statistical analysis and correlated comparison test. From the results of data analysis it can be stated that the application of the discovery learning model by integrating virtual laboratory and high order thinking can improve the learning outcomes of students including knowledge, attitudes, science process skills aspect and problem solving skills. Thus, the application of the discovery learning model by integrating virtual laboratory and high order thinking has given a positive effect in improving learning outcomes of students.
\end{abstract}

Keywords : Discovery learning model, Virtual laboratory, Hots, Learning outcomes

(i) This is an open access article distributed under the Creative Commons 4.0 Attribution License, which permits unrestricted use, distribution, and reproduction in any medium, provided the original work is properly cited. 02018 by author and Universitas Negeri Padang.

\section{PENDAHULUAN}

Pelaksanaan pembelajaran seharusnya mampu memupuk dan mengembangkan kompetensi abad ke-21 siswa. Dalam pembelajaran, siswa perlu memiliki kompetensi ini agar dapat berhasil baik dalam pembelajaran maupun dalam kehidupan sehari-hari. Kompetensi abad ke-21 dapat didefinisikan sebagai suatu kombinasi dari kemampuan dalam aspek pengetahuan, keterampilan, sikap, dan nilainilai (Saavedra \& Opfer, 2012; Wang et al., 2018). Keseimbangan dari aspek kompetensi ini adalah penting bagi siswa agar dapat berhasil baik dalam belajar, kehidupan sehari-hari maupun masa depan mereka. Dengan demikian, guru perlu menciptakan pembelajaran yang mampu mengembangkan kompensi siswa secara holistik dalam abad ini.

Pembelajaran yang mendorong pengembangan kompetensi siswa secara holistik perlu diterapkan oleh guru dengan baik. Dengan dasar ini, pembelajaran yang dilaksanakan seharusnya mempunyai konteks yang relevan, berpusat kepada siswa, memberikan makna, dan mempunyai keterkaitan dengan kehidupan masyarakat (Wulandari, 2016). Pembelajaran memiliki konteks artinya materi pembelajaran perlu dikaitkan dengan situasi dunia nyata. Pembejaran berpusat kepada siswa berarti dalam pembelajaran siswa banyak terlibat dalam mengkonstruksi kompetensi. Pembelajaran bermakna berarti dalam pembelajaran siswa mengalami suatu peristiwa secara langsung sehingga informasi yang diperoleh tersimpan lama dalam ingatannya. Disisi lain, pembelajaran terkait dengan masyarakat berarti materi pembelajaran tidak jauh berbeda dengan kehidupan masyarakat sehari-hari.

Pembelajaran yang diterapkan dalam kurikulum 2013 adalah pembelajaran yang dapat mengembangkan pengetahuan, keterampilan, dan sikap. Ketiga aspek kompetensi siswa ini dibangun 
dalam kegiatan inti. Dengan alasan ini, pembelajaran harus mampu memotivasi siswa belajar, memberikan aspirasi, memberikan tantangan, mendorong kreativitas siswa dan sebagainya. Ada beberapa pembelajaran yang disarankan dalam kurikulum 2013, yaitu pembelajaran penemuan, pembelajaran inkuiri, pembelajaran berbasis masalah, pembelajaran berbasis proyek (Riyanto, 2016; Hanafi, 2016). Dengan demikian, guru perlu mempelajari, menguasai, dan menerapkan pembelajaran ini dengan baik untuk membangun kompetensi siswa secara holistik.

Namun, kondisi nyata yang ditemukan di SMA Negeri 10 Padang belum sesuai dengan kondisi ideal. Kondisi nyata pertama adalah adanya keterbatasan set eksperimen dan waktu pembelajaran untuk mendukung penerapan model pembelajaran penemuan atau model inkuiri. Kondisi nyata kedua berhubungan kurangnya keterampilan siswa dalam memecahkan soal-soal berpikir tingkat tinggi. Mereka umumnya cendrung menggunakan rumus yang sudah ada atau rumus yang praktis untuk memecahkan soal-soal Fisika. Kondisi nyata ketiga adalah nilai rata-rata ulangan harian Fisika masih berada pada kategori rendah. Adanya kesenjangan antara kondisi nyata dengan kondisi ideal ini mengindikasikan masalah untuk diteliti.

Suatu alternatif pemecahan masalah adalah penerapan model pembelajaran penemuan mengintegrasikan laboratorium virtual dan keterampilan berpikir tingkat tinggi (Hots). Pemilihan solusi ini didasarkan pada karakteristik dari pembelajaran sains seperti fisika. Kegiatan eksperimen adalah penting dalam Fisika untuk menjelaskan dan mendeskripsikan suatu fenomena fisika dan karakteristiknya (Asrizal et al., 2018). Dasar dari pembelajaran sains adalah pemahaman fenomena alam dan sifat-sifat dari sains yang memerlukan penyelidikan dan penemuan. Penyelidikan dalam sains terdiri dari eksperimen dan penyelidikan fenomena alam dengan pembelajaran penemuan (Balim, 2009). Penemuan merupakan suatu cara untuk menemukan pengetahuan dari tidak diketahui menjadi mengetahui oleh siswa sendiri. Partisipasi aktif dari siswa dalam proses pembelajaran disebut pembelajaran penemuan (Joy, 2014). Bruner menyatakan bahwa pembelajaran dengan penemuan akan terjadi apabila ada perioritas pada refleksi, berpikir, eksperimen dan eksplorasi (Balim, 2009; Anyafulude, 2014; Emerhiona, 2018). Pembelajaran penemuan didasarkan pada teori belajar konstruktivisme. Karena itu, dalam pembelajaran penemuan siswa mengkonstruksi pengetahuan didasarkan informasi baru dan data yang dikumpulkan oleh mereka dalam suatu lingkungan belajar eksploratif (Joy, 2014; Vanichvasin, 2018).

Dalam perencanaan pembelajaran, pembelajaran penemuan dapat dipandang sebagai suatu model pembelajaran. Model pembelajaran merupakan suatu rencana yang dapat digunakan untuk membentuk mata pelajaran, mendesain materi pembelajaran dan memandukan kegiatan guru (Mangal, 2009; Subramani, 2017; Asrizal, 2018). Suatu model pembelajaran terdiri dari panduan untuk mendesain kegiatan pendidikan dan lingkungan belajar (Pateliya, 2013). Model pembelajaran penemuan adalah suatu model pembelajaran yang mendorong siswa membangun pengetahuannya sendiri dengan melakukan eksperimen untuk menemukan prinsip dari eksperimen (Rahman, 2017). Sebagai suatu model, model pembelajaran penemuan memiliki sintak tertentu. Ada enam fase dari model pembelajaran penemuan yang dapat dijadikan sebagai acuan bagi guru dalam pembelajaran, yaitu: stimulasi, identifikasi masalah, pengumpulan data, pengolahan data, pembuktian, dan generalisasi (Mushtoza, 2016; Irmita, 2018; Suardana, 2018).

Laboratorium virtual dapat digunakan untuk mendukung penerapan dari model pembelajaran penemuan. Laboratorium virtual dapat didefinisikan sebagai eksperimen laboratorium tanpa laboratorium nyata yang memungkinkan siswa untuk menghubungkan aspek teoritis dan aspek praktis. Laboratorium ini diprogram secara elektronik dalam komputer untuk untuk mensimulasikan eksperimen nyata dalam laboratorium nyata (Babate, 2011). Laboratorium virtual menyediakan versi simulasi dari laboratorium tradisional yang berkenaan dengan pembelajaran berpusat pada siswa. Penggunaan laboratorium virtual memberikan kontribusi pada proses pembelajaran dengan memberikan kepada siswa peluang untuk belajar dengan bekerja, memberikan daya tarik kepada siswa, menyediakan kegiatan menyenangkan untuk mendorong mereka menemukan, dan menjamin adanya interaksi kelas yang aktif melalui diskusi (Faour, 2018). Ada beberapa keuntungan dari penggunaan laboratorium virtual dalam pembelajaran, yaitu: eksperimen membutuhkan waktu yang pendek, melaksanakan eksperimen dalam lingkungan yang aman, menghasilkan peristiwa kembali 
yang tidak mungkin diobservasi dalam laboratorium nyata dalam lingkungan virtual, menjadi solusi alternatif untuk biaya laboratorium yang mahal, memberikan umpan balik kepada siswa secara langsung dengan cara memeriksa pembelajaran mereka (Asiksoy, 2017). Phet merupakan salah satu laboratorium virtual yang menyediakan simulasi sains dan matematika didasarkan riset yang menyenangkan, bebas, dan interaktif. Phet adalah singkatan dari Physics Education Technology yang menyediakan untuk melakukan simulasi dalam pembelajaran Fisika, Biologi, Kimia dan Matematika yang dapat diunggah secara gratis untuk kepentingan pembelajaran (Sapurwoko et al., 2017).

Penerapan model pembelajaran penemuan mengintegrasikan laboratorium virtual dan berpikir tingkat tinggi diperkirakan dapat memecahkan masalah penelitian ini. Dengan alasan ini, peneliti tertarik untuk menerapkan model ini dalam pembelajaran Fisika. Tujuan dari penelitian adalah untuk menyelidiki efek dari penerapan model pembelajaran penemuan untuk meningkatkan hasil pembelajaran siswa pada aspek pengetahuan, keterampilan dan sikap.

\section{METODE PENELITIAN}

Jenis penelitian yang dilakukan adalah penelitian tindakan kelas (PTK). Pelaksanaan penelitian diawali dengan adanya permasalahan dalam pembelajaran Fisika siswa kelas XI SMA Negeri Padang. Desain penelitian yang digunakan dalam PTK adalah model siklus yang dikembangkan oleh Kemmis dan Taggart. Model ini dikenal juga dengan model spiral yang terdiri dari empat komponen, yaitu: perencanaan, pelaksanaan, pengamatan, dan refleksi.

Pada setiap komponen pada siklus terdiri dari beberapa kegiatan. Kegiatan pada perencanaan terdiri dari: menganalisis kompetensi inti dan kompetensi dasar fisika SMA kelas XI; memahami fasefase model pembelajaran penemuan; dan menyiapkan perangkat pembelajaran Fisika kelas XI seperti silabus, rencana pelaksanaan pembelajaran, lembar kerja siswa, dan lembar tugas dengan soal hots. Kegiatan pada pelaksanaan adalah menerapkan fase-fase model pembelajaran penemuan dalam kegiatan pendahuluan, kegiatan inti, dan kegiatan penutup. Kegiatan observasi dilakukan untuk mengamati penerapan model pembelajaran penemuan, ketarampilan proses sains, dan sikap siswa. Disisi lain, kegiatan refleksi dilakukan setelah menerapkan model pembelajaran penemuan untuk mengevaluasi kekuatan dan kelemahan yang ditemukan pada observasi.

Penelitian ini merupakan suatu penelitian kolaboratif antara dosen dengan guru Fisika SMA Negeri 10 Padang. Pelaksanaan penelitian berlangsung selama dua siklus. Setiap siklus terdiri enam kali pertemuan. Setiap pertemuan berlangsung selama 2 jam pelajaran. Berarti jumlah total pertemuan untuk kedua siklus adalah 12 kali pertemuan di luar ulangan harian. Jumlah siswa yang terlibat dalam penerapan model pembelajaran penemuan adalah 32 orang.

Pada penerapan model pembelajaran penemuan mengintegrasikan laboratorium virtual dan Hots siklus I ditemukan beberapa kelemahan. Secara umum ada empat kelemahan pada siklus I, yaitu: ada $50,0 \%$ nilai hasil belajar siswa aspek pengetahuan masih rendah dari 66 , nilai rata-rata keterampilan proses sains masih berada pada kategori cukup, keterampilan pemecahan soal-soal Hots masih rendah, dan masih banyak muncul sikap negatif siswa dalam pembelajaran. Revisi tindakan yang diterapkan pada siklus II adalah membuat grup WA dengan siswa, memperjelas instruksi pada LKS, menyakinkan pentingnya kompetensi kepada siswa, meningkatkan motivasi belajar siswa, meningkatkan keakraban dengan siswa, dan memberikan jawaban di WA untuk pemecahan soal yang tidak tuntas.

Instrumen untuk mengumpulkan data terdiri atas tiga bagian, yaitu tes tertulis, lembar penilaian kinerja, dan lembar observasi sikap. Tes tertulis digunakan untuk mengetahui aspek pengetahuan siswa setelah siklus I dan siklus II. Secara umum tes tertulis dapat dibagi atas dua kelompok yaitu tes objektif dan essay. Lembar penilaian kinerja siswa digunakan untuk menilai keterampilan proses sains siswa dalam model pembelajaran penemuan. Sementara itu, lembar observasi digunakan untuk mendapatkan data aspek sikap siswa selama penerapan model pembelajaran penemuan.

Data penelitian dianalisis dengan statistik deskriptif dan uji perbandingan berkorelasi. Statistik deskriptif digunakan untuk mendeskripsikan kelompok data dari aspek pengetahuan, keterampilan, dan sikap. Deskripsi dari kelompok data ditampilkan dalam bentuk tabel dan grafik. Uji perbandingan berkorelasi digunakan untuk menentukan perbedaan yang berarti antara aspek pengetahuan pada siklus 
I dengan siklus II. Tujuannya adalah untuk menyelidikan pengaruh dari revisi perlakuan yang dilakukan pada siklus II.

\section{HASIL DAN PEMBAHASAN}

\section{Hasil Belajar Siswa Pada Aspek Kognitif}

Setelah menerapkan model pembelajaran penemuan mengintegrasikan laboratorium virtual dan Hots pada siklus I diberikan postes kepada siswa. Kelemahan-kelemahan yang ditemukan pada siklus I direvisi dan dimasukkan pada perencanaan pada siklus II. Setelah menerapkan model pembelajaran penemuan dengan revisi dilakukan pula postes pada siklus II. Data hasil postes pada siklus I dan siklus II dianalisis dengan statistik yang sesuai. Hasil analisis data dari postes siklus I dan siklus II dapat diperhatikan pada Tabel 1

Tabel 1. Nilai Parameter Statistik dari Data Tes Akhir Siklus I dan Siklus II

\begin{tabular}{llcc}
\hline \multirow{2}{*}{ Statistik } & \multicolumn{1}{c}{ Parameter } & Siklus I & Nilai \\
\cline { 3 - 4 } Statistik deskriptif & Rata-rata & 66,17 & 77,34 \\
& Median & 68,10 & 80,00 \\
& Modus & 75,00 & 80,00 \\
& Deviasi standar & 8,77 & 10,32 \\
& Variansi & 76,91 & 106,43 \\
& Minimum & 45,00 & 35,00 \\
& Maksimum & 80,00 & 90,00 \\
Uji normalitas & Range & 35,00 & 55,00 \\
Uji homogenitas & P-value & $<0,005$ & $<0,005$ \\
Wilcoxon signed rank test & P-value & \multicolumn{2}{c}{0,37} \\
\hline
\end{tabular}

Dari data pada Tabel 1 dapat dikemukakan bahwa nilai rata-rata aspek kognitif siswa pada siklus I dan siklus II masing-masing 66,17 dan 77,34. Kedua nilai rata-rata hasil belajar ini sudah berada pada kategori baik. Nilai rata-rata hasil belajar aspek kognitif siswa siklus II lebih tinggi dari hasil belajar siswa pada siklus I dengan kenaikan sebesar 11,17. Adanya perbedaan nilai rata-rata hasil belajar siswa pada aspek kognitif ini mengindikasi kan adanya pengaruh dari revisi tindakan yang dilakukan pada siklus II.

Data hasil belajar aspek kognitif pada siklus I dan siklus II tidak mempunyai distribusi normal. Disisi lain, data dari kedua hasil belajar siklus I dan siklus II mempunyai varians yang sama. Bertitik tolak pada hasil uji normalitas dan homogenitas berarti data hasil belajar aspek kognitif dari siklus I dan siklus II tidak memenuhi statistik parametrik. Dengan alasan ini, uji perbandingan yang digunakan untuk menganalisis data adalah uji ranking tanda Wilcoxon. Dari uji perbandingan ini didapatkan nilai $Z=-6,97$. Nilai $Z$ ini berada di luar daerah penerimaan hipotesis Ho. Hal ini berarti adanya revisi tindakan yang dilakukan pada siklus II memberikan perbedaan yang berarti pada hasil belajar aspek kognitif. Dengan demikian, revisi tindakan pada siklus II memberikan pengaruh yang berarti terhadap peningkatan hasil belajar siswa pada aspek kognitif.

\section{Hasil Belajar Siswa Pada Aspek Keterampilan Proses Sains}

Penilaian terhadap aspek keterampilan siswa dinilai selama penerapan model pembelajaran penemuan mengintegrasikan laboratorium virtual dan Hots. Aspek keterampilan yang dinilai adalah keterampilan proses sains. Ada tujuh indikator dari aspek keterampilan proses sains yang dinilai, yaitu: menanggapi stimulus (M1), menyatakan masalah (M2), merumuskan hipotesis (M3), mengumpulkan data (M4), mengolah data (M5), membuktikan hipotesis (M6), dan menyimpulkan (M7). Data dari setiap indikator keterampilan proses sains dianalisis dengan statistik deskriptif. Nilai rata-rata dari setiap indikator keterampilan proses sains pada siklus I dan siklus II ditampilkan pada Gambar 1. 


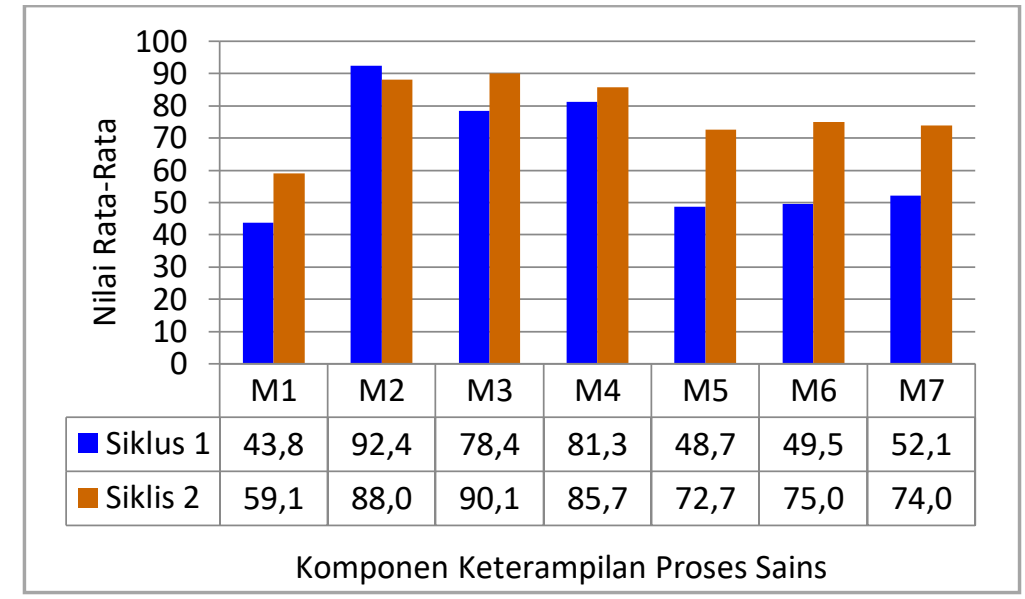

Gambar 1. Nilai Rata-Rata Aspek Keterampilan Proses Sains Siswa

Dari analisis data pada Gambar 1 dapat dijelaskan bahwa nilai rata-rata indikator keterampilan proses sains pada siklus I bervariasi antara 43,8 sampai 92,4. Ada dua indikator keterampilan proses sains yang sudah berada pada kategori sangat baik, yaitu menyatakan masalah dan mengumpulkan data, sedangkan indikator merumuskan hipotesis berada pada kategori baik. Sementara itu, empat indikator keterampilan proses sains masih berada pada kategori kurang, yaitu menanggapi stimulus, mengolah data, membukti hipotesis, dan menyimpulkan. Nilai rata-rata dari ketujuh indikator dari aspek keterampilan proses sains adalah 63,7. Nilai rata-rata aspek keterampilan proses sains siswa pada siklus I masih berada pada kategori cukup. Pada siklus II, nilai rata-rata indikator aspek keterampilan proses sains bervariasi antara 59,1 sampai 90,1. Indikator dari keterampilan proses sains yang sudah berada pada kategori sangat baik pada siklus II ada tiga, yaitu menyatakan masalah, merumuskan hipotesis, dan mengumpulkan data. Tiga indikator yang berada pada kategori baik, yaitu mengolah data, membuktikan hipotesis, dan menyimpulkan. Disisi lain, indikator menanggapi stimulus masih berada pada kategori cukup. Nilai rata-rata dari ketujuh indikator aspek keterampilan proses sains pada siklus II adalah 77,8 dan nilai rata-rata ini berada pada kategori baik. Jadi, revisi tindakan pada siklus II dapat meningkatkan nilai rata-rata keterampilan proses sains siswa dari 63,7 menjadi 77,8 .

\section{Keterampilan Pemecahan Soal Hots Siswa}

Data keterampilan siswa memecahkan soal-soal Hots diambil dari postes dalam bentuk essai pada siklus I dan siklus II. Dari pemecahan soal siswa dinilai keterampilan pemecahan soal dalam lima indikator, yaitu: memfokuskan masalah, mendeskripsikan fisika dari soal, merencanakan pemecahan, mengeksekusi rencana pemecahan, dan menemukan jawaban dari soal. Nilai keterampilan pemecahan soal siswa pada siklus I dan siklus II dapat diperhatikan pada Gambar 2.

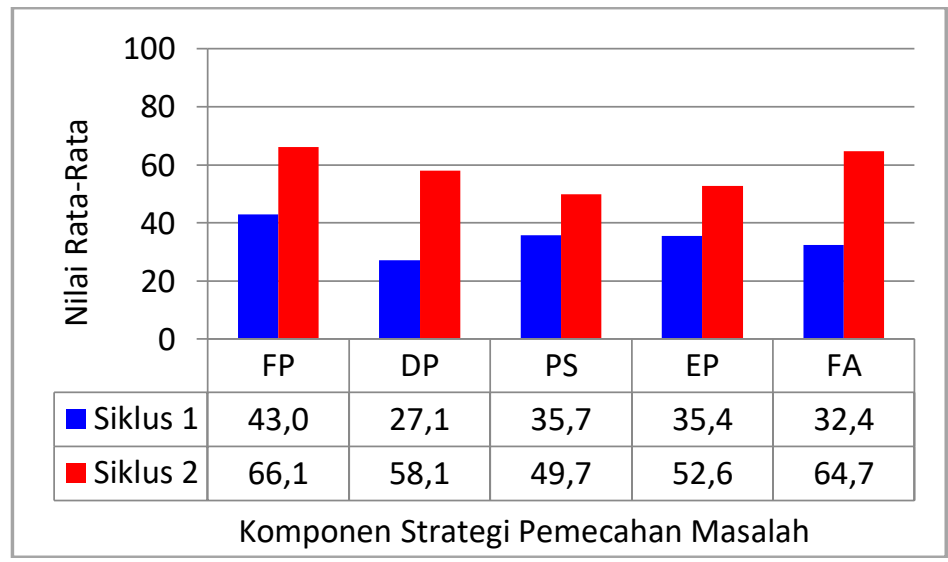

Gambar 2. Nilai Keterampilan Pemecahan Masalah Soal Hots Siswa 
Berdasarkan hasil analisis data pada Gambar 2 dapat dijelaskan bahwa nilai indikator pemecahan soal Hots siswa berada antara 27,1 sampai 43,00. Pada siklus I, hanya satu indikator yang berada pada kategori kurang, yaitu memfokuskan masalah. Sementara itu, empat indikator keterampilan pemecahan masalah lainnya masih berada pada kategori sangat kurang atau gagal, yaitu mendeskripsikan fisika dari soal, merencanakan pemecahan, mengeksekusi rencana, dan menemukan jawaban dari soal. Nilai rata-rata dari kelima indikator keterampilan pemecahan soal adalah 34,7 dan nilai rata-rata ini berada pada kategori sangat kurang. Pada siklus II, nilai indikator keterampilan pemecahan soal bervariasi dari 49,7 sampai 66,1. Nilai keterampilan pemecahan soal yang sudah berada pada kategori baik pada siklus kedua adalah memfokuskan masalah. Nilai indikator menggambarkan fisika dari soal dan menemukan jawaban berada pada kategori cukup, sedangkan dua indikator lainnya masih berada pada kategori kurang, yaitu merencanakan pemecahan dan mengeksekusi rencana. Nilai rata-rata keterampilan pemecahan soal Hots siswa pada siklus kedua adalah 58,3. Nilai rata-rata keterampilan pemecahan soal ini berada pada kategori cukup.

\section{Hasil Belajar Siswa Pada Aspek Sikap}

Pada saat penerapan model pembelajaran penemuan mengintegrasikan laboratorium virtual dan Hots dilakukan pengamatan terhadap aspek sikap siswa. Ada enam indikator sikap siswa yang diamati dalam proses pembelajaran, yaitu: percaya diri, disiplin, kerja keras, kerjasama, komitmen inkuiri dan tanggung jawab. Pada masing-masing siklus dilakukan pengamatan terhadap indikator aspek sikap selama tiga minggu untuk enam kali pertemuan. Data dalam bentuk skor dikonversi kedalam bentuk nilai. Data sikap dianalisis dengan statistik deskriptif dalam bentuk grafik. Nilai rata-rata dari setiap indikator sikap pada siklus I dan siklus II ditampilkan pada Gambar 3.

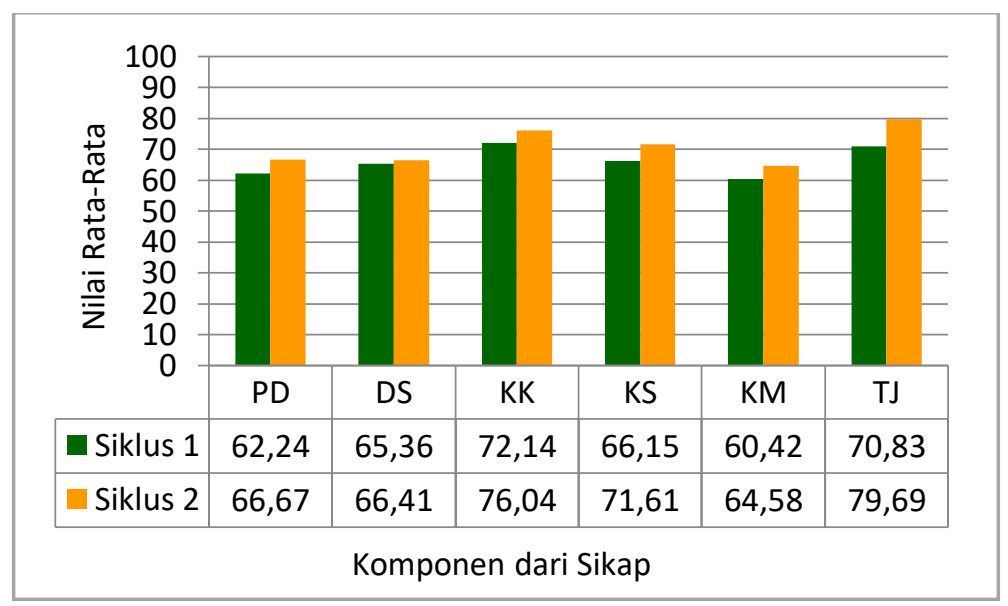

Gambar 3. Nilai Rata-Rata dari Aspek Sikap Siswa

Berdasarkan data pada Gambar 3 dapat dinyatakan bahwa nilai rata-rata indikator aspek sikap siswa pada siklus I bervariasi antara 60,42 sampai 72,14. Ada tiga indikator sikap pada siklus pertama yang sudah berada pada kategori baik, yaitu kerja keras, kerjasama dan tanggung jawab sedangkan tiga indikator sikap lainnya masih berada pada kategori cukup, yaitu percaya diri, disiplin, dan komitmen inkuiri. Nilai rata-rata dari keenam indikator sikap siswa adalah 66,19 . Nilai rata-rata ini dapat dimasukkan pada kategori baik. Nilai rata-rata indikator aspek sikap siswa pada siklus II bervariasi antara 64,58 sampai 79,69. Pada siklus II, ada lima indikator aspek sikap yang sudah berada pada kategori baik, yaitu percaya diri, disiplin, kerja keras, kerjasama dan tanggung jawab, sedangkan satu indikator aspek sikap masih berada pada kategori cukup yaitu komitmen inkuiri. Nilai rata-rata dari keenam aspek sikap siswa pada siklus II adalah 77,83 dan nilai rata-rata ini berada pada kategori baik. Dengan demikian, revisi tindakan yang dilakukan pada siklus II dapat meningkatkan nilai ratarata sikap siswa dari 66,19 menjadi 77,83 .

Penerapan model pembelajaran penemuan mengintegrasikan laboratorium virtual dan Hots telah mampu meningkatkan hasil pembelajaran siswa terutama aspek pengetahuan, keterampilan proses sains, dan sikap siswa. Hal ini dapat terjadi karena karakteristik dari model pembelajaran penemuan 
dan laboratorium virtual yang telah diterapkan dalam pembelajaran fisika. Penerapan pembelajaran penemuan dapat mendorong rasa ingin tahu, mengalami penyelidikan, dan menemukan pengetahuan (Balim, 2009). Dengan pembelajaran penemuan siswa terlibat aktif untuk memperoleh konsep dan prinsip (Tompo, 2016). Model pembelajaran penemuan memberikan efek yang berarti pada kemampuan berpikir kritis dan kognitif siswa (Martaida, 2017). Penggunaan laboratorium virtual dalam model pembelajaran penemuan melatih siswa dalam menerapkan proses sains mencakup menyatakan masalah, merumuskan hipostesis, mengumpulkan data, menguji hipostesis, dan menyimpulkan. Penerapan pembelajaran penemuan dapat meningkatkan keterampilan proses sains siswa (Ayadiya, 2015). Laboratorium virtual menyediakan pengalaman virtual yang bermakna, menyajikan konsep, prinsip, dan proses penting dalam pembelajaran. Berarti laboratorium virtual menyediakan peluang kepada siswa untuk mengulang eksperimen yang tidak benar atau untuk memperdalam pengelaman dalam proses sains. Hasil penelitian menunjukkan bahwa visualisasi fenomena melalui komputer memberikan kontribusi pada penguasaan konsep fisika siswa (Ranjan, 2017). Disamping itu, penerapan proses ilmiah dalam model pembelajaran penemuan dapat menumbuhkan sikap ilmiah siswa (Al Rabadi, 2013). Hasil-hasil penelitian ini relevan dengan hasil penelitian Suendarti (2017) yang menyatakan bahwa model pembelajaran penemuan memberikan efek yang berarti pada hasil pembelajaran dari ilmu pengetahuan alam siswa.

\section{KESIMPULAN}

Kesimpulan dari penelitian didapat dari analisis data yang telah dilakukan. Dari analisis data dapat dinyatakan bahwa penerapan model pembelajaran penemuan mengintegrasikan laboratorium virtual dan Hots dapat meningkatkan kinerja siswa pada aspek pengetahuan, keterampilan proses sains, keterampilan pemecahan soal, dan sikap. Pada aspek pengetahuan, nilai rata-rata siswa meningkat dari 66,17 menjadi 77,34 dengan kedua nilai rata-rata ini berada pada kategori baik. Nilai rata-rata keterampilan proses sains meningkat dari 63,6 menjadi 77,8 . Nilai rata-rata keterampilan siswa dalam memecahkan soal-soal Hots meningkat dari 34,7 menjadi 58,3. Disisi lain, nilai rata-rata sikap siswa meningkat dari 66,19 menjadi 77,83. Dari hasil ini dapat direkomendasikan kepada guru Fisika untuk menerapkan model pembelajaran penemuan untuk meningkatkan kinerja siswa terutama pada aspek pengetahuan, keterampilan proses sains, dan sikap siswa. Penerapan model pembelajaran penemuan mengintegrasikan laboratorium virtual dan Hots belum memberikan hasil yang memuaskan dalam aspek keterampilan pemecahan soal Hots.

\section{DAFTAR PUSTAKA}

Al Rabadi, I.G.S., Al Momami, H.O.S., \& Al Rabadi, K.I.S. (2013). The Effect of Using Process Approach on Science Achievement and Scientific Attitudes among Jordanian Basic Stage Students. Journal of Education and Practice, 4 (20), 136-150.

Anyafulade, J.C. (2013). Effects of Problem-Based and Discovery-Based Instructional Strategies on Students' Academic Achievement in Chemistry. Journal of Educational and Social Research, 3 (6), 105-111.

Asiksoy, G., \& Islek, D. (2017). The Impact of the Virtual Laboratory on Students'Attitudes in a General Physics Laboratory. International Journal of Online Engineering (iJOE), 13 (4), 20-28.

Asrizal, A., Yohandri, Y., \& Zulhendri, K. (2018). Studi Hasil Pelatihan Analisis Video dan Tool Pemodelan Tracker pada Guru MGMP Fisika Kabupaten Agam. Jurnal Eksakta Pendidikan, 2 (1), 41-48.

Asrizal, A., Amran, A., Ananda, A., Festiyed, F. (2018). Effectiveness of Adaptive Contextual Learning Model of Integrated Science by Integrating Digital Age Literacy on Grade VIII Students. IOP Conf. Series: Materials Science and Engineering 335 (2018) 012067, 1-8.

Ayadiya, N., \& Sumarni, W. (2015). The Application of Discovery Learning With Scientific Approach to Improve The Students' Science Process Skill. Proceedings of The 9th Joint Conference on Chemistry, 466-469.

Babaten, H.M. (2011). The Role of Virtual Laboratories in Science Education. 5th International Conference on Distance Learning and Education, 12 (2011), 100-104. 
Balim, A.G. (2009). The Effects of Discovery Learning on Students' Success and Inquiry Learning Skills. Eurasian Journal of Educational Research, 35, 1-20.

Emerhiona, F.A., Nwanze, A.C., Pius, P.O., \& Izuegbuna, A.G. (2018). Effects Of Problem And Discovery-Based Instructional Strategies On Students' Academic Achievement In Chemistry. International Journal of Innovative Research and Advanced Studies, 5 (6), 209-214.

Faovor, M.A., \& Ayoubi, Z. (2018). The Effect of Using Virtual Laboratory on Grade 10 Students' Conceptual Understanding and their Attitudes towards Physics. Journal of Education in Science, Environment and Health (JESEH), 4 (1), 54-68.

Hanafi. (2016). The Effect of Discovery Learning Method Application on Increasing Students' Listening Outcome and Social Attitude. Dinamika Ilmu, 16 (2), 291-306.

Irmita, L., \& Atun, S. (2018). The Influence of Technological Pedagogical and Content Knowledge (TPACK) Approach on Science Literacy and Social Skills. Journal of Turkish Science Education, 15 (3), 27-40.

Joy, A. (2014). Impact of Discovery-Based Learning Method on Senior Secondary School Physics. IOSR Journal of Research \& Method in Education, 4 (3), 32-36.

Mangal, S.K., \& Mangal, U. (2009). Essesntial of Education Technology. New Delhi: PHI Learning Private Limited.

Martaida, T., Bukit, N., \& Ginting, E.M. (2017). The Effect of Discovery Learning Model on Student's Critical Thinking and Cognitive Ability in Junior High School. IOSR Journal of Research \& Method in Education, 7 (6), 01-08.

Musthoza, D.A. (2016). Discovery Learning in Teaching Report Writing for Junior High School Students Based on 2013 Curriculum. Indonesian Journal of English Teaching (IJET), 5 (1), 5577

Pateliya, Y.P. (2013). An Introduction to Modern Models of Teaching. International Journal for Research in Education, 2 (2), 125-129.

Rahman, M. H. (2017). Using Discovery Learning to Encourage Creative Thinking. International Journal of Social Sciences \& Educational Studies, 4 (2), 98-103.

Ranjan, A. (2017). Effect of Virtual Laboratory on Development of Concepts and Skills Physics. International Journal of Technical Research \& Science, 2 (1), 15-21.

Riyanto., Aryulina, D. (2016). A Problem Based Learning Model in Biology Education Courses to develop Inquiry Teaching Competency of Preservice Teachers. Cakrawala Pendidikan, XXXV (1), 47-57.

Suardana, I.N., Redhana, I.W., Sudiatmika, I.A.R., \& Selamat, I.N. (2018). Students' Critical Thinking Skills in Chemistry Learning Using Local Culture-Based 7E Learning Cycle Model. International Journal of Instruction, 11 (2), 399-412.

Suedarti, M. (2017). The Effect of Learning Discovery Model on the Learning Outcomes of Natural Science of Junior High School Students Indonesia. International Journal of Environmental \& Science Education, 12 (10), 2213-2216.

Saavedra, A.R., \& Opfer, V.D. (2012). Teaching and Learning 21 st Century Lesson from the Learning Sciences. Asia Society, Partnership for Global Learning. 1-35.

Subramani, N. (2016). Effective Teaching and Learning. United states : Lulu Publication.

Supurwoko., Cari., Sarwanto., Sukarmin., Budiharti, R., \& Dwi, T.S. (2017). Virtual Lab Experiment: Physics Educational Technology (PhET) Photo Electric Effect for Senior High School. International Journal of Science and Applied Science: Conference Series Int. J. Sci. Appl. Sci.: Conf. Ser., 2 (1), 381-386.

Tompo, B., \& Ahmad, A., \& Muris, M. (2016). The Development of Discovery-Inquiry Learning Model to Reduce the Science Misconceptions of Junior High School Students. International Journal of Environmental \& Science Education, 11 (12), 5676-5686.

Vanichvasin, P. (2018). Using an Interactive Learning Book Based on Interactive and Discovery Learning to Enhance Student Interaction and Achievement. Assumption Business Adminitration College (ABAC) Journal, 38 (1), 
Wang, Y., Lavonen, J., \& Tirri. (2018). Aims for Learning 21st Century Competencies in National Primary Science Curricula in China and Finland. EURASIA Journal of Mathematics, Science and Technology Education, 14 (6), 2081-2095.

Wulandari, S.P., Budiyono., \& Slamet, I. (2016). The Development of Learning Module with Discovery Learning Approach in Material of Limit Algebra Functions. International Conference on Mathematics, Science, and Education, M-165 sd M-170. 